\title{
ENTRE TENSÕES E (CON) TRAdiÇões: A FORMAÇÃO AUTÔNOMA DA LITERATURA
}

\author{
Among the tensions and contradictions: the autonomous formation of \\ Brazilian
}

\section{Entre las tensiones e (con) tradicciones: la formación autónome de la lit- eratura brasileña}

\author{
Keissy Guariento Carvelli ${ }^{1}$ \\ Ricardo André Ferreira Martins ${ }^{2}$
}

Resumo: A pesquisa consiste num panorama histórico-cultural acerca da formação e consolidação da Literatura Brasileira partindo das tônicas essenciais de autonomia literária e nacionalismo tendo em vista a consolidação do projeto de cânone romântico brasileiro e pelas movimentações promovidas por intelectuais tais como José de Alencar (1829-1877) e Gonçalves Dias (1823-1864).

Palavras-chave: Cânone. História da literatura. Língua Portuguesa. Literatura Brasileira. Romantismo.

\begin{abstract}
The research consists of a cultural historical panorama about the formation and consolidation of the Brazilian literatura with such autonomy literary, as well as nationalim with a view to the consolodation of the draft movement promoted by brazilian intelectual of romantic canon essential features such as José de Alencar (1829-1877) and Gonçalves Dias.
\end{abstract}

Keywords: Canon. History of literature. Portuguese Language. Brazilian. Literature Portuguese Language. Romanticism.

Resumen: Esa investigación consiste en presentar un panorama histórico cultural acerca de la formación y consolidación de la Literatura Brasileña con características específicas tales como la autonomía literaria y el nacionalismo los cuales se pretendían la consolidación del proyecto de constitución de un Canon romántico brasileño, movimiento promovido por intelectuales nacionalistas tales como José de Alencar (1829-1877) y Gonçalves Dias (1823-1864).

Palabras clave: Historia de la literatura. Literatura brasileña. Romanticismo. Canon. Idioma Portugués.

1 Universidade Estadual do Centro-Oeste.

2 Universidade Estadual do Centro-Oeste.

\begin{tabular}{|c|c|c|c|}
\hline $\begin{array}{l}\text { TEL IRATI (PR)/Ponta Grossa (PR) } \\
\text { Dol } 10.5935 / 2177-6644.20150004\end{array}$ & V.6 N.1 P. $41-52$ & JAN./JUN. 2015 & E-ISSN: 2177-6644 \\
\hline
\end{tabular}




\section{INTRODUÇÃO}

"[...] o que é brasileiro é brasileiro, e que cuya virá a ser tão clássico como porcellana, ainda que a não achem tão bonita"

Gonçalves Dias

Pensar a História da Literatura Brasileira é um exercício que prescinde a tomada de consciência de alguns aspectos particulares à história político-social e também linguística do país, isso porque, embora tenhamos atualmente conceitos bem aparados acerca de Literatura Brasileira e Língua Portuguesa (brasileira), as relações que fundamentam ambos os campos estão imersas em acontecimentos tanto contraditórios quanto férteis, suscitando análises mais dialógicas e menos limitadas, ampliando a compreensão da nossa ainda recente produção literária e intelectual, visto que contamos com pouco mais de dois séculos de uma efetiva sistematização da escrita em território brasileiro. Em primeira instância, o fato da colonização aponta em nosso passado - seja político ou literário - uma constante preocupação em torno da autonomia, sendo o tom fundamental que define a linha de encaminhamento na constituição da história - e também da crítica - literária brasileira nos primeiros séculos da nascente civilização brasileira. Tom fundamental porque não somente o território indígena entrava em contato com colonizadores que mudariam em definitivo as relações deste povo com sua terra, mas principalmente pelo fato da colonização trazer consigo uma arma imprescindível à dominação efetiva dos povos: a língua.

Os primeiros relatos de cronistas e jesuítas que desembarcaram no Brasil no século XVI são coesos à representação de um tipo de torre de Babel, ou seja, um mesmo território aglutinando diversas línguas, todavia com a peculiaridade de apresentarem certa homogeneidade linguística e cultural principalmente no decorrer de toda a bacia do Paraná/Paraguai (Cf. MATTOS E SILVA, 2001) ${ }^{3}$. Neste sentido, se a multiplicidade de línguas ${ }^{4}$ - e de povos - é característica da população indígena logo na chegada da colonização, poucos anos depois este quadro já nos mostra realidades bastante diferentes e objetivos bastante claros.

Para um esclarecimento mais apurado, estudos elaborados por Mattos e Silva (2001), tendo como fonte Alberto Mussa, afirmam que de 1538 a 1600 o Brasil contava com uma população indígena de $50 \%$; europeus já somavam 30\%; e 20\% de africanos. Já de 1851 a 1890 , a estimativa é de apenas $2 \%$ de índios; $17 \%$ europeus; $24 \%$ brancos brasileiros; $42 \%$ mulatos; $13 \%$ negros brasileiros e $2 \%$ africanos. Em aspectos históricos, um dos fatores fundamentais para o desaparecimento de grande parte das variações linguísticas presentes no Brasil é a dizimação indígena nos primeiros séculos de colonização, sem contar a massiva chegada de europeus e africanos na condição de escravos que acabaram por contribuir com a dominação praticamente completa da língua portuguesa, tornando-nos um território unilíngue. Não é a população indígena, portanto, a responsável pela disseminação da língua que sairia vitoriosa no Brasil do século XVIII, ao contrário, as línguas indígenas foram aprendidas pelos jesuítas fundamentalmente como "[...] parte

3 A autora aponta para a predominância desta característica em grupos indígenas do tronco linguístico tupi; também os tupinambás e os tupiniquins, que embora sejam grupos inimigos apresentam semelhanças linguísticas que os aproximam.

4 De acordo com Rodrigues (1986 apud MATTOS; SILVA, 2001), há 180 línguas indígenas sobreviventes, ao passo que hipoteticamente à chegada da colonização este número seria em torno de 300 , com forte tendência a ser um número ainda maior. 
de seu programa catequético [...]"(MATTOS; SILVA, 2001, p. 285). Assim, a população escrava - e de negros e mulatos libertos - é também responsável ainda que indireta pela disseminação da língua portuguesa - e pelas suas variações - entre os povos das terras brasílicas, que em contato diário com os senhores tinham de aprender a linguagem da ordem dada.

Muito embora a língua - tal qual a história - seja personagem viva e esteja em constante movimento, é preciso considerar os aspectos histórico-literários que traçam os percursos pelos quais língua e literatura irão caminhar de sua nascente dependência até a sua estimada autonomia. Isto porque foi fundamental o papel da instituição do cânone brasileiro literário enquanto um compasso medidor dos raios de padronização da arte escrita brasileira: aquilo que foge à circunferência traçada naturalmente não está inscrito sob a alcunha necessária da literatura. Desse modo, embora incutida de ares libertadores, o advento da história e crítica literária brasileira além de ser concomitante à escrita da própria literatura, atua também tal qual um imperativo categórico (Cf. LEÃO, 2013) para a formação de uma história da Nação, ou ainda de uma identidade cultural de uma Nação. História e Literatura se imbricam ao mesmo tempo em que se subsidiam, de forma que se temos um passado de histórias oficiais e pouco críticas, no berço literário brasileiro também temos um infante com vestimentas oficiais e títulos de honrarias.

Uma língua por decreto numa sociedade analfabeta

A formação da língua portuguesa falada no Brasil constitui-se de maneira pluralizada: por um lado existiam as línguas indígenas dizimadas; de outro, o português do europeu - do culto ao mais iletrado -, e finalmente as línguas africanas dos escravos (Cf. MATTOS
E SILVA, 2001). Todavia, não podemos crer na tese de que a ação mais ou menos instintiva dos escravos seja o fator primordial desta vitória da língua portuguesa. Ações políticas bem demarcadas foram essenciais para a consolidação desta unidade linguística que viria a se tornar regra em todo o território brasileira. Ao que aponta Vitral (Cf. MATTOS E SILVA, 2001), o primeiro fato determinante desta vitória foi a política de Marquês de Pombal que em 1758 torna obrigatório o uso da língua portuguesa na colônia; além disto, a política também previu uma revisão do ensino praticado em terras brasileiras, ou seja, a instrução aos índios -catequização e regras morais basicamente - ministradas pelos jesuítas a partir daquele momento torna-se função do Estado português.

A partir deste decreto pombalino, não somente uma língua era definitivamente imposta, o ainda insípido sistema de ensino fora duramente interrompido com a categórica expulsão dos jesuítas do território brasileiro resultando “[...] na destruição do sistema de ensino colonial, pois inicialmente nada foi organizado para substituí-lo" (RIBEIRO, 2002, p. 363). Não se trata de afirmar que em pleno período colonial funcionasse um sistema organizado e consolidado de Educação: os jesuítas contavam com apenas 17 colégios e seminários, e somente em 1638 foi ofertado o curso de Filosofia no Colégio do Rio de Janeiro, dando início ao ensino superior brasileiro. No entanto, se tais cursos já se restringiam apenas aos filhos de colonos, com a política de Pombal tais cursos fechariam as portas e somente treze anos mais tarde o Brasil retomaria um projeto inicial de Educação, e consequentemente do ensino da língua portuguesa (Cf. RIBEIRO, 2002).

O segundo fato imprescindível é a vinda de D. João VI e da corte portuguesa para a colônia (que significou uma população 
a mais de 15 mil portugueses e falantes da língua portuguesa no Brasil), além da criação de novas necessidades relacionadas aos interesses do rei. Até a data de chegada da corte ao Rio de Janeiro, toda e qualquer prática do conhecimento era proibida: desde a impressão de livros à fundação de Universidades, bem como o funcionamento de uma imprensa, tais atividades eram expressamente proibidas à submissa colônia brasílica de Portugal. Com a transferência desta parte da população portuguesa para cá tal cenário se modifica, e a proibição deixa de ser válida. No entanto, é preciso ressaltar que a não proibição não significa a possibilidade de acesso ao conhecimento pela grande população brasileira.

Os dados apresentados por Vitral (2001) comprovam que não era prioridade do Estado Português o ensino da língua, tampouco a instituição de escolas no início do século XIX: em 1818 estima-se que apenas 2,5\% da população masculina livre tinha acesso à educação na cidade de São Paulo; somado a isso havia apenas 12 mil alunos matriculados em colégios secundários, enquanto o número de pessoas com educação superior chegava a 8 mil (MATTOS E SILVA apud FAUSTO, 2001, p. 279). O número de letrados segundo os estudos da autora apontam para uma mínima porcentagem de $0.5 \%$ no Brasil nos três séculos coloniais. $\mathrm{O}$ que não seria muito diferente nos século XVIII e XIX.

Se por um lado tínhamos uma massa populacional falando um português abrasileirado - uma mistura da língua portuguesa com elementos da língua africana e também indígena -, de outro tínhamos uma restrita elite que tomava contato com cursos educacionais, podendo ser considerados como falantes de um português culto; ou seja, éramos um oceano de analfabetos diante d'uma gota de letrados. Cabe-nos ressaltar que não houve política educacional destinada a este oceano de escravos e trabalhadores em geral, ao passo que um aparato de cursos superiores e viagens à Coimbra faziam parte do itinerário educacional destinado à fina gota dos recém-chegados da Europa. Este tipo de política autoritária - e excludente - evidentemente que não proporcionou $o$ desenvolvimento de um sistema educacional voltado ao ensino da Língua Portuguesa a aqueles considerados analfabetos, favoreceu, é fato, a consolidação de uma pequena elite com condições financeiras para iniciar os estudos no Brasil e terminá-los na Europa.

Comefeito, desdeos princípioscoloniais podemos considerar o fato da língua como “[...] uma marca de classe social e, dentre todas as instituições sociais, a que mais fortemente se impõe aos indivíduos [...]" (CALLOU, 2002, p. 283); neste caso específico a língua portuguesa ao mesmo tempo em que é imposta à colônia é também negada aos nascentes cidadãos brasileiros. Será esse português europeu - falado por portugueses das mais variadas formações - inclusive analfabetos - a base histórica do português culto brasileiro que tem o início de sua fundamentação a partir da segunda metade do século XVIII, propiciando discussões linguísticas posteriores que constituem um dos eixos principais da formação de uma literatura nacional no século XIX com o Romantismo.

\section{LITERATURA APÊNDICE NÃO FAZ HISTÓRIA: A BUSCA POR UMA LITERATURA AUTÔNOMA}

De início, e de caráter político, podemos apontar a problemática da nascente Literatura Brasileira do século XIX girando em torno de dois momentos históricos decisivos para a organização social do país, incluindo os campos da educação e das artes (em específico a literatura): a) chegada da corte portuguesa 
ao Rio de Janeiro no ano de 1808; b) o fato da independência política de Portugal, em 1822. São momentos importantes porque um é responsável pela inserção da cultura das letras no Brasil (com a corte vem a liberação da imprensa, da impressão de livros, etc.); outro porque influi diretamente na reivindicação de uma independência política de Portugal, mas essencialmente porque é também sob este espírito que se dá a constituição do projeto Romântico e do espírito nacional que permeará todo o campo das belas-letras brasileiras, sempre sob o vislumbre de um processo civilizador.

Até o que se conhece como o processo da independência (que não se dá efetivamente ao sete de setembro, tampouco aí se finda), não estava somente $\mathrm{o}$ Brasil enquanto status político ligado a Portugal: a literatura aqui produzida - ainda que escassa- era considerada algo como um apêndice da grande história da Literatura Portuguesa. No entanto, o nosso longo século XIX ${ }^{5}$ que abarcou da Independência de 1822 à Proclamação da República em 1889 apresentou uma série de tensões e contradições também no campo linguístico que, se não fundamentam, ao menos contribuem para a consolidação de um nascente Estado-nação brasileiro que, embora apresente ares de independência, constituise sob princípios bastante discutíveis. Os encaminhamentos políticos determinantes para a separação política entre Brasil e Portugal não apresentam profundas relações com a identidade libertária, por exemplo, menos ainda representam possibilidades de mudanças sociais efetivas. Como afirma categoricamente Maria Odila Leite Silva Dias,

[...] os ideais liberais não surgiram como um programa modernizador do conjunto das forças sociais: foram veiculados por

5 O Breve Século XX, de Eric Hobsbwan. uma minoria ilustrada e culta [...]. Essa minoria de letrados, inspirada nos ideais do despotismo ilustrado do século XVIII, reservava para si a missão paternalista de modernizar e reformar o arcabouço político e administrativo do país [...]. Não respondia, a impulsos internos de transformação social, mas as forças externas de pressão, principalmente da Inglaterra, no sentido de integração do Brasil, como Estado independente, no novo sistema de equilíbrio internacional, gerado pelo desenlace das guerras napoleônicas (2005, grifo nosso, p. 128).

Capistrano de Abreu (Cf. COUTINHO, 1972) em estudos acerca da literatura nacional - na década de 1930 - afirma que efetivamente a Independência não influiu mudança nem teve por objetivo um projeto de organização em muitos aspectos sociais do Brasil, em especial na educação; Neves ainda reforça a centralização da educação já a essa época: “[...] em inícios do oitocentos, a educação [...] servia às elites como uma espécie de ornamento a fim de distingui-la da massa [...]" (NEVES, 2002, p. 54). Evidentemente que o tipo de política instaurada no início do país independente prioriza relações muito pouco voltadas ao território nacional e à população como um todo, neste sentido, língua e literatura servem como um ornamento e encontram-se num palco de disputas políticas bastante demarcadas entre portugueses e brasileiros. De modo que até meados do século XIX a literatura brasileira é uma história da literatura apêndice ${ }^{6}$,

6 Os primeiros estudos que tratam de autores brasileiros apresentam somente um ou outro escritor, com escassas informações e essencialmente sob a perspectiva da Literatura Portuguesa, à pena da escrita européia. Ao que aponta Guilhermino César (1978) em seus estudos e traduções, o alemão e filósofo Bouterwek (1765-1828) inicia inédito estudo com a obra História da Poesia e da Eloqüência Portuguesa, ainda em 1805. Seguindo pelos mesmos caminhos, César (1978) nos apresenta Simonde de Sismondi (1773-1842) e Ferdinand Denis (1798-1890) como pensadores fundamentais para a disseminação dos ideias românticos que viriam a penetrar em toda a prática e teoria 
baseando tal distinção diante do fato da língua portuguesa. Mas as agitações emancipatórias e sociais que tornaram possível a separação política de Portugal foram fundamentais também para que eclodissem correntes de pensadores que reclamassem uma literatura própria, uma literatura literalmente brasileira.

Não se pode exatamente delimitar até que ponto as ideias políticas separatistas influenciam a literatura, ou até que ponto ideias políticas e literárias se fundem em homens públicos atuantes em espaços dos mais diversos. Neste sentido, nos anos que sucedem o fato da independência, a jovem Nação - principalmente a cidade do Rio de Janeiro - conta com intelectuais e homens de letras a fim de consolidar uma independência não somente política, mas também cultural, assim a consolidação do campo das letras funciona também como carro chefe para a constituição de uma identidade cultural nacional,

Somente a afinidade entre o movimento romântico, o nascimento de uma nova pátria e o nosso desejo de fundar uma literatura nacional explica a razão pela qual o Romantismo adaptou-se tão bem às nossas necessidades e demandas durantes o século XIX, a ponto de fundamentar e fundar a teleologia de nossa identidade cultural. (LEÃO, 2013, p. 603).

Para Eric Hobsbawn em Nações e Nacionalismos (1990), embora teoricamente a afirmação de uma Nação nascente devesse corresponder a critérios como um território mais ou menos homogêneo e políticas unificadas, não eram de fato estes os critérios que fundamentaram a formação liberal das

da nossa literatura - principalmente através de Madame de Stäel e Almeida Garret - nos anos seguintes , tais como: o nacionalismo, a autonomia, a peculiaridade, unidade, etc. nações europeias, e também de Portugal e Brasil posteriormente. Na prática, destaca, há três critérios fundamentais aos ideólogos da época que possibilitam a um povo ser definitivamente classificado como Nação, sendo: a) a associação histórica deste Estado com outro já existente - ou seja, com um passado que o afirme; $b$ ) a existência de uma elite cultural longamente-estabelecida, além de um vernáculo administrativo e literário escrito; c) uma provada capacidade para a conquista de território, especificamente. (HOBSBAWN, 1990, p. 49-50). Tais concepções de Estado-nação, de acordo com o historiador, fundamentaram $\mathrm{o}$ triunfo do liberalismo burguês que se dá de 1830 a 1880, ideais esses que pela constante atualização da Corte diante do pensamento europeu inspiravam intelectuais e políticos brasileiros que pretendiam colocar em curso um processo civilizador brasileiro a estes modos. Ora, Portugal bem ou mal dava conta de ser um Estado pré-existente ao brasileiro, contando ainda com um passado razoavelmente capaz de fundar um Estadonação, desse modo o primeiro critério - ainda que com pouco mérito - pode ser cumprido; a prova de dominação territorial Portugal já dera durante os séculos de colonização; em pleno século XIX, então, restava-nos apenas a consolidação de uma elite cultural com um vernáculo escrito que desse alcunhas gloriosas à identidade cultural brasileira.

Aquilo que precede o advento do Romantismo é uma ebulição de ideias e práticas que culminam numa crença bastante homogênea entre literatos, políticos e intelectuais - frequentemente todas estas atividades concentravam-se num homem só - de que a poesia servia tal como um “[...] instrumento pedagógico e, portanto, civilizatório [...] a fim de formar cidadãos mais ilustrados" (LEÃO, 2013, p. 578). Homens 
como José Bonifácio de Andrada e Silva, por exemplo, representa o que Coutinho (1974) denomina de pré-romântico, cuja importância se dá pela influência que exerce para a primeira geração brasileira de literatos, principalmente disseminando valores literários bastante peculiares que viriam a compor o quadro de inspiração de nossos primeiros românticos, tais como os que aponta França citado por Leão (2013): “[...] o cultivo das letras como ornamento intelectual" (p. 582); a atuação intelectual em campos diversos como a política, o jornalismo, produção cultural, estudos científicos, práticas pedagógicas, etc; a própria concepção da literatura enquanto agente de uma missão civilizatória; e principalmente a intenção de conferir traços nacionais à cultura do Brasil. Trata-se, deste modo, da construção de uma identidade nacional, no entanto bem aparada e restrita ao círculo da pequena burguesia agroescravista disposta a comandar o País independente ${ }^{7}$.

O tom que emerge no século XIX - e que o permeia até meados do XX -, então, é o de um nacionalismo fundador tanto político quanto culturalmente, cabendo também ao campo das Letras movimentações fundamentais com vistas à consolidação de uma língua e literatura próprias dando rumo e sentido aos processos de formação de um

\footnotetext{
7 Prática comum que antecede o Romantismo - e que se mantém tal como uma tradição também durante o século XIX - são os sermões cheios de retóricas, exaltações nacionalistas e fervor poético que inspirou boa parte dos jovens talentos que fundariam uma cultura brasileira literária. Sermonistas como Sousa Caldas, São Carlos, Januário da Cunha Barbosa e Monte Alverne são citados por Ricardo Leão (2013) como responsáveis pelo nascente entusiasmo eloqüente dos nossos homens de letras. A prática colonial dos sermões permanece durante grande parte da história cultural brasileira, isto porque em pouquíssimos momentos da história do Brasil existiu uma preocupação efetiva com o ensino de línguas. Assim, a maioria da população sempre esteve longe da cultura literária propriamente dita, sendo a oratória uma saída efetiva, já que privilegia a disseminação de ideias entre todos os homens, aliado ao fato de que os sermões servem bem à catequização e doutrinamento.
}

Estado-nação. A busca por uma literatura autônoma se dá, portanto, diante de um conjunto de formulações que pretendem nacionalizar tanto a literatura quanto a língua, neste sentido, o projeto romântico atua tanto enquanto fundador de um projeto estético de cânone baseado em princípios bem atrelados do campo político, tais como o nacionalismo, a autonomia atrelada às concepções de independência.

\section{Projeto ROMÂnTICo: RUPTU- RAS E TRADIÇÕES LITERO-LIN- GUÍSTICAS}

A consolidação do Movimento Romântico teve como projeto de cânone instituído aquele promovido pela revista Niterói (1836), grupo encabeçado por Gonçalves de Magalhães (1811-1882), cujo objetivo principal consistia em "[...] definir uma literatura nova no Brasil, que fosse no plano da arte o que fora a Independência na vida política e social [...]" (CÂNDIDO, 1981, p.12), assim, literatos como José de Alencar (1829-1877) e Gonçalves Dias (1823-1864) representam o esforço em exaltar peculiaridades que reforcem um caráter cultural próprio, independente. Uma independência um tanto às avessas, já que grande parte dos ideais românticos difundidos tanto na literatura, quanto na história e filosofia, por exemplo, são oriundos de pensadores alemães e franceses, basicamente. Elementos como o indianismo e patriotismo, desta maneira, atuam enquanto projeto estético que define e ao mesmo tempo instaura os conceitos de uma Literatura Brasileira. Projeto literário confunde-se aí com projeto político bem delimitado, fazendo da poesia espaço destinado ao canto da terra, evocando de poetas e intelectuais muito mais que uma mera participação criativa na cultura 
local: durante todo o período romântico existiu um tipo de dever patriótico, fazendo com que as belas-letras atuassem também enquanto instituição capaz de solidificar o Estado-nação tendo em suas obras efetiva colaboração ao progresso.

O dever patriótico muito mais que atenuar progressos e nacionalismos favoreceu os movimentos para a consolidação de uma Literatura autônoma, não sem gerar conflitos, já que muito embora o país vivesse sob o aspecto de independência, tornar-se efetivamente autônomo denotava em tensões diretas também no campo da linguagem. Inicialmente a primeira geração do grupo romântico procura acentuar sucessivas negações, principalmente no que tange aos excessos de lusitanismos no interior de obras literárias. Surgindo como um movimento de negação (Cf. CÂNDIDO, 1981, p. 23), a primeira geração romântica tende a consolidar seu projeto estético partindo do repúdio a quase tudo o que era Português, instaurando novas concepções de linguagem literária, inspirações locais, e principalmente evocando novos pensamentos sobre "[...] o lugar do homem no mundo e na sociedade" (CÂNDIDO, 1981, p. 23).

Para além do dever patriótico, e da colocação do Brasil na marcha civilizatória, contribuições significativas dos poetas românticos se acentuam no que tange à realidade linguística brasileira, e é aí que o Romantismo se apresenta em definitivo como um projeto literário revolucionário, ao passo que promove discussões ferrenhas acerca dos usos da Língua Portuguesa no Brasil, e da excessiva tentativa por parte de Portugal de concentrar e normatizar a língua usada por aqui por aqueles de lá. Personagem central da nascente crítica literária, José de Alencar aprimorou tentativas de integração nacional por meio da literatura, e fundamentou concepções valiosas no que tange à língua, numa tentativa de promover também neste aspecto uma independência. Para tanto, pretendeu conceituar a língua enquanto "[...] nacionalidade do pensamento como a prática é a nacionalidade do povo" (COUTINHO, 1974, p. 108).

Colocando a linguagem em movimento, o cearense possibilita reflexões que inauguram não somente o campo da crítica, mas principalmente a língua sob um novo estado de consciência, atribuindo aos próprios brasileiros autonomia para modificála à sua realidade, de modo que seja também a língua capaz de exprimir seu povo. Como já salientado aqui, o cenário linguístico brasileiro apresentava tantas miscigenações quanto suas populações: palavras indígenas foram mantidas para referenciais coisas daqui, assim como as entonações africanas foram modificando alguns termos portugueses, no entanto tais desvios não eram vistos com bons olhos pela minoria dirigente e intelectuais luso-brasileira, de tal modo que desvios da gramática em textos escritos eram frequentemente usados como maneira de desqualificar seu autor, qualificando outros de escrita mais pura, que nada mais representa que aquela escrita pautada pelas normas portuguesas e por palavras pouco conhecidas por aqui.

José de Alencar em seu Pós escrita de Diva nos atenta para o fato linguístico como motivo de distinção entre colonizadores e o povo brasileiro em geral:

Há de saber que nossos irmãos de origem e língua riem-se de nosso povo brasileiro porque diz moro na rua de...,estou na Janela, cheguei em casa [...] (COUTINHO, 1974, p. 161)

deste modo, a exigência do literato é a de que tais desvios nada mais são que o exercício do próprio povo em cunhar na língua a sua "[...]individualidade, abrasileirando o instrumento das idéias" (COUTINHO, 1974, 
p. 160). Para o romancista em 1874 em Carta ao Sr. Joaquim Serra, inibir os sucessivos movimentos da linguagem portuguesa em solo brasileiro seria como "[...] aleijar nossa língua tão rica” (COUTINHO, 1974, p.162), admitindo ser necessária uma revolução também da língua, ao que denomina de "[...] dialeto brasileiro" (COUTINHO, 1974, p. 175). Seria, então, um atraso ao país que se torna independente politicamente cultivar ideias conservadoras tanto da língua quanto da literatura. Gonçalves Dias (18231864), do mesmo modo, pretende lançar à língua reflexões que permitam ao brasileiro aumentá-la, enriquecê-la, promovendo então uma língua moldada às suas próprias necessidades. Ao defender a língua do povo, o poeta evidentemente tributa em causa própria: considera válidas as modificações introduzidas na língua portuguesa por "[...] necessidades e as imposições dos costumes e coisas locais" (COUTINHO, 1974, p. 62), afirmando, então, uma “[...] língua dos escritores brasileiros" (COUTINHO, 1974, p. 62). Assim, para Dias,

Se a literatura é a linguagem carregada de significado, a língua que mais convém à literatura de um povo é aquela que esse povo fala e entende" (COUTINHO, 1974, p. 62).

Não era somente o vocabulário da língua praticada no Brasil que se estendia e distinguia do de Portugal, também a sintaxe o fazia de forma menos formal, de modo que para os críticos e literatos seria impraticável uma língua portuguesa brasileira aos moldes do desenvolvimento da língua portuguesa de Portugal; da mesma forma, se a língua deveria desse modo tomar sua autonomia, também caberia à Literatura tal distinção. Para além de um projeto literário pautado em novas conceituações do campo da estética, da temática e da lírica, o Romantismo ancorou suas primeiras navegações sob a perspectiva da língua, provocando rupturas significativas no campo da produção cultural brasileira. Mas não sem alguns conflitos ${ }^{8}$.

Para além das exaltações ufanistas da terra das palmeiras, sabiás, da cor local, de Iracema; para além da mistificação do índio enquanto bom selvagem, dos verdes tão mais verdes, o Romantismo promoveu profundas reflexões linguísticas que em muito contribui para uma atualização sobre os aspectos literários do próprio povo brasileiro. Ainda na década de 1840, em carta endereçada a Dr. Pedro Nunes Leal, Gonçalves Dias atenta para um fator determinante a toda Nação que pretende instituir um projetoliterário ecultural que de fato esteja integrado à sua população em geral: o conhecimento da língua. Afirma ser essencial ao bom escritor o conhecimento preciso da língua em que escreve, já que a “[...] a língua é a parte material, mas indispensável das concepções do espírito". (COUTINHO, 1974, p. 63). Se estamos falando em produzir uma arte escrita, tal como a literatura, tornase impossível o desconhecimento da língua que se pretende exprimir, no caso a Língua Portuguesa, bem como as línguas indígenas, e também africanas que de uma forma ou de outra dialogam e se impõem à língua portuguesa praticada no Brasil.

No entanto, ao mesmo tempo que exige veementemente uma mudança da língua portuguesa, afirma “[...] que só uma coisa fica e deve ficar eternamente respeitada a

8 Muitos foram os conflitos conceituais proporcionados por escritores que se opunham ao grupo romântico emergente. Ricardo Leão (2013) aponta para o caso de Gama e Castro que apresenta uma coerente tese que contraria a determinação em tornar autônoma a Literatura produzida no Brasil, já que ainda que sob distinções territoriais, toda a literatura se denomina por sua língua, não pela sua nacionalidade, e se a língua falada e escrita aqui é a portuguesa - ainda que com acréscimos e desvios - deveria então ser a Literatura também Portuguesa. 
gramática e o gênio da língua" (COUTINHO, 1974). Mesmo com traços marcantes de reivindicação de uma autonomia tanto da língua quanto da literatura, o poeta não deixa de respeitar a gramática portuguesa, deixando que um diálogo entre tradição e modernidade também soassem na instituição do Romantismo.

Bom ou mau grado, a língua tupi lançou profundíssima raízes no português que falamos e nós não podemos, nem devemos atirá-los para um canto a pretexto de que a outros parecer bárbaros e mal soantes. [...] Clássico ou não clássico - Pernambuco é Pernambuco, cajá, paca e outros semelhantes, não tem outro nome. Se isso desagrada a Portugal, é grande pena, mas não tem remédio (COUTINHO, 1974, p. 65).

Neste sentido, ao passo que os intelectuais do romantismo lançam discussões que pretendem promover mudanças conceituais quanto a beleza, consciência literária, e também da língua, acabam por fundar um projeto estético que servirá como espinha dorsal para toda a produção literária posterior praticada no Brasil. Ou seja, aquilo que inicialmente se coloca enquanto um movimento de negação (Cf. CÂNDIDO, 1981), e até mesmo como ruptura linguística (Cf. SAGUIER, 1982) instaura-se enquanto a consolidação de um cânone, principalmente em figuras como Gonçalves Dias.

\section{Conclusão}

Se à época da colonização poucos esforços foram dados em relação ao ensino da Língua Portuguesa à população local, o pós-independência não se caracteriza por um cenário muito diferente: em 1872, entre os escravos o analfabetismo estava estimado em 99,9\%; entre a população livre aproximadamente $80 \%$. Tal situação se estende até o final do século XIX:

Dentre os ideais da proclamação da República (1889) estava a preocupação com a educação, com a erradicação do analfabetismo, com a expansão da educação. Foi criado, então, o Ministério da Instrução Pública Correios e Telégrafos, entregue a Benjamim Constant, caracterizando, assim, a primeira manifestação mais significativa de preocupação com a educação. De 1891 a 1910 foram criadas 27 escolas superiores, embriões de futuras universidades (RIBEIRO, 2002, p. 365).

Muito embora tenhamos de 1830 aos finais do século XIX um intenso trabalho de letrados, políticos e intelectuais, a situação extra-oficial não era muito animadora no que concerne à preocupação com a população local e a sua participação efetiva dos entraves políticos e culturais do país. Somente em 1923 teríamos a fundação de uma primeira universidade brasileira, e, tal como a obrigatoriedade da língua portuguesa por Marquês de Pombal, cria-se através de um decreto9. (Cf. RIBEIRO, 2002). Deste modo, devemos considerar que não foi a educação quem inseriu a população brasileira à língua portuguesa, muito pelo contrário, serviu antes como forma de distinção entre aqueles poucos letrados - e frequentemente mal formados - daqueles iletrados, e analfabetos por completo. Assim, a formação de um campo literário autônomo se dá ao mesmo tempo em que princípios como a educação da língua é deixado de fora dos projetos políticos contribuindo com a intensificação do caráter

\footnotetext{
9 A razão do decreto é muito simples, e pouco tem a ver com aspectos educacionais: por ocasião de uma visita do rei da Bélgica, deveria o Itamarati dar a ele um título de Doutor Honoris causa, assim, por falta de instituição capaz de conferir-lhe tal feito, cria-se a Universidade do Brasil. (Cf. RIBEIRO, 2002).
} 
de missão atribuído aos intelectuais e homens públicos.

Embora a lírica romântica esteja delineada sob aspectos ufanistas, de exaltação do povo e das belezas naturais de sua terra, é no terreno da legitimação da língua portuguesa que apresenta maior representatividade. Isto porque, para Pierre Bourdieu, "A língua legítima não tem o poder de garantir sua própria perpetuação no tempo nem o de definir sua extensão no espaço" (2008, p. 45), ou seja, se a língua portuguesa sai vitoriosa diante das múltiplas línguas que no Brasil existiam, teve o projeto Romântico efetiva participação ao dotar de valores simbólicos o mito do índio herói, bem como a integração nacional pela literatura. Se por um lado representaram rupturas no que concerne à adoção de palavras abrasileiradas na escrita da literatura, por outro também favoreceram as imposições da tradição colonial, ao forjar uma história mitológica do povo brasileiro aos moldes dos cavaleiros medievais.

Não por acaso o projeto literário brasileiro muitas vezes concorda com os princípios políticos elaborados. Como já fora levantado, poucos eram os homens que organizavam politicamente o Brasil, assim, ao mesmo tempo em que exerciam funções públicas importantes, também serviam à intelectualidade, as belas-letras, à prática da crítica, etc. Não raro tais intelectuais omitem elementos que colocam o Brasil sob posição crítica, como por exemplo a precária preocupação com a educação no século XIX, os índices de analfabetismo exacerbados, a escravidão como fonte de renda das elites agroescravistas, a dizimação dos índios, etc. Se os "[...] costumes lingüísticos não são passíveis de modificação por decreto" (BOURDIEU, 2008, p. 38), no Brasil tal decreto - aquele de Pombal ainda no século XVIII - teve colaboração (ainda que indireta) de todo um aparato político e cultural que lhe deu validade. Tínhamos no século XIX um país independente, um projeto literário autônomo, uma língua autônoma, e uma população analfabeta. De modo que a formação de um campo literário autônomo fora imprescindível também ao projeto político de Nação, atuando assim a literatura como legitimador de políticas que em raros casos teve em vista a população brasileira. No entanto, se "[...] uma obra de arte é boa quando surge de uma necessidade" (RILKE, 2008, p. 26), o Romantismo é uma obra de arte em si, já que em sua origem há valor necessário para fomentar reflexões por todo o período que o subsegue, "É no modo como ela se origina que se encontra seu valor, não há nenhum outro critério". (RILKE, 2008, p. 27).

\section{REFERÊNCIAS}

CALLOU, D. Da História social à História Lingüística: O Rio de Janeiro no século XIX. In: ALKMIN, T. M. (Org.). Para a história do Português Brasileiro, v. III: Novos Estudos. São Paulo: Humanitas/FFLCH/USP, 2002. p. 281-292.

BOURDIEU, P. A economia das Trocas Lingüísticas: o que falar quer dizer. São Paulo: Universidade de São Paulo, 2008.

CANDIDO, A. Formação da Literatura brasileira: momentos decisivos. 6. ed. Belo Horizonte: Ed. Itatiaia, 1981. 
COUTINHO, A. (Org.). Caminhos do pensamento crítico. Vol. II, Rio de Janeiro: Americana, Prolivro, 1974.

Caminhos do Pensamento Crítico. v. I, Rio de Janeiro: Pallas; Brasília: INL, 1972.

LEÃO, R. Os atenienses e a invenção do cânone nacional. São Luís: Instituto Geia, 2013.

MATTOS E SILVA, R. V. De fontes sócio-históricas para a história social lingüística do Brasil: em busca de indícios. In: (Org.). Para a história do português brasileiro. v.II, Tomo II. São Paulo: Humanitas/FFLCH/USP: FAPESP, 2001. p. 275-301.

MELLO, H. R. Português padrão, português não-padrão e a hipótese do contato lingüístico In: ALKMIN, T. M. (Org.). Para a história do Português Brasileiro. v. III: Novos Estudos. São Paulo: Humanitas/FFLCH/USP, 2002. p. 341-358.

VITRAL, L. Língua geral versus Língua Portuguesa: A influência do Processo Civilizatório. In: MATTOS E SILVA; R. V. (Org.). Para a história do português brasileiro. vol.II, tomo II. São Paulo: Humanitas/FFLCH/USP: FAPESP, 2001. p. 303-315.

RIBEIRO, I. Quais as faces do português culto brasileiro? In: ALKMIN, T. M. (Org.). Para a história do Português Brasileiro. v. III: Novos Estudos. São Paulo: Humanitas/FFLCH/USP, 2002. p. 359-381.

RILKE, R. M. Cartas a um jovem poeta. Porto Alegre: L\&PM, 2008. 